\title{
PASTOR WERNER FUCHS: UMA BIOGRAFIA CONSTRUÍDA NUMA PRÁXIS POLÍTICA-RELIGIOSA
}

Werner Fuchs, pastor da Igreja Evangélica Luterana no Brasil (IECLB), é um personagem cuja biografia merece atenção especial pela sua inserção e influência histórica. Leitura e postura religiosa/política, raciocínio rápido, persuasão nas palavras e conhecimento das humanidades, pastor Fuchs viveu no Oeste do Paraná num dos momentos de maiores transformações sociais e políticas ocorridas no meio rural e urbano. Transcorre a segunda metade da década de 1970 em que o 'cenário oestino' está marcado pelo intenso êxodo rural, concentração fundiária, urbanização rápida não planejada, implementação do mega projeto militar da construção da hidrelétrica de Itaipu, entre outros.

Neste contexto tenso/intenso, a trama é composta por diversos personagens figurando entre eles os agricultores e comerciantes que se tornam expropriados pela formação do lago da Itaipu. A metodologia adotada pela Itaipu para proceder às indenizações das propriedades rurais e urbanas é o mote principal que sensibiliza o surgimento de lideranças ligadas, sobretudo, as religiões católica e protestante. A consolidação desta ação marcaria nacionalmente a história dos movimentos sociais. Na organização de reuniões, na elaboração e publicações de panfletos e jornais, na formação de lideranças, na articulação com lideranças políticas em nível regional e nacional, aparece a figura do pastor Fuchs como intelectual orgânico, na expressão gramsciniana, dos movimentos sociais que assumem uma postura de esquerda, embora não se denominem enquanto tal.

A entrevista a seguir foi construída durante os meses de outubro de 2006 a março de 2007, via e-mail, num diálogo intenso e pulsante de experiências porque 
rememorava momentos ricos de um fazer individual e coletivo. O objetivo principal da conversa visava compreender como um personagem de intensa militância à frente de movimentos sociais e com uma biografia construída junto à religião luterana, compreendia o papel da Igreja Católica no Oeste do Paraná, sobretudo da ação de Dom Olívio Fazza, bispo da diocese de Foz do Iguaçu, diante o processo de implementação do projeto de construção de Itaipu e sua co-relação social.

A entrevista não pode ser lida, nem as informações serem interpretadas, sem ter conhecimento da práxis conjuntural da Igreja Católica nas décadas de 1970/80 e a vigência do regime militar que ainda mostrava as garras de um poder centralizador. O diálogo a seguir ousou levantar algumas questões culturais que, contudo, mostra-se limitada pela própria natureza da publicação. O desafio de novos rumos e a possibilidade de explorar práticas e representações culturais estão lançadas.

\section{1- Sua experiência pastoral na região Oeste do Paraná remete a década de} $1970 ?$

R - Fui pastor da Igreja Evangélica de Confissão Luterana no Brasil (IECLB) em Santa Helena de outubro de 1979 até julho de 1982. No entanto, assumi a coordenação da Comissão Pastoral da Terra do Paraná (CPT-PR) em Cascavel junto com um ex-padre, coordenador da Associação de Estudos, Orientação e Assistência Rural (Assesoar), Claudino Veronese, já no final de agosto de 1978, em um encontro da pastoral rural. Aí soube da sagração episcopal de Dom Olívio ${ }^{1}$. Claudino e eu viajamos para o encontro da CPT em Goiânia. Depois fui fazer as

\footnotetext{
${ }^{1}$ Dom Olívio Aurélio Fazza foi o primeiro bispo da diocese de Foz do Iguaçu tendo tomado posse em 26 de agosto de 1978. Hoje, com 82 anos de idade, é bispo emérito daquela diocese e atua como vigário geral.
} 
despedidas da paróquia em Santa Catarina (Arabutã). Mudei-me para Marechal Cândido Rondon no final de setembro, assumindo o escritório da CPT. As atividades abrangiam, sobretudo o Oeste do Paraná (atingidos de Itaipu, posseiros, Notas Promissórias Rurais, entre outros). No início de 1979 veio trabalhar comigo um estudante de teologia. Como vagou a Paróquia de Santa Helena, assumimos juntos o atendimento em dois finais de semana por mês. Depois, fui convidado a assumir o trabalho em definitivo, mas a Paróquia concordou que eu dedicasse até 10 dias por mês à CPT (o escritório da CPT foi transferido de Marechal Cândido Rondon para Curitiba anos depois). Ao sair de Santa Helena, demorei quase dois meses (tratamento de saúde e definição de nova paróquia: Maringá), mas carreguei minha mudança antes que subissem as águas da Itaipu (outubro de 1982).

\section{2- Quais foram os maiores desafios pastorais enfrentados a frente da comunidade?}

R-Desafios maiores: a) capacitação de lideranças e formação de equipes, sobretudo porque eu não podia atender todos os trabalhos (catequeses, jovens, música, etc.) e, ainda, cuidar dos conflitos de terra, coordenando as ações da CPT. Tratava-se, na época, de uma das maiores paróquias da IECLB: 16 comunidades e 6 pontos de pregação, dispersos por Entre Rios, Santa Helena, Missal e São Miguel do Iguaçu (hoje Itaipulândia). Mas, havia muita compreensão da parte da diretoria e dos membros, porque praticamente metade deles eram atingidos diretos da Itaipu, e outros sofreriam indiretamente; b) o contexto de violência e repressão política prefeitos nomeados, vereadores omissos, proximidade do Paraguai, permitindo a 
fuga de criminosos - a situação conflitiva por terras devolutas, cheias de posseiros, etc. Tanto mais surpreendente é o surgimento de movimentos sociais.

3- A convivência entre as religiões Luterana e Católica era pacífica na região? Havia causas comuns que as enlaçavam pastoralmente?

R- A convivência havia sido construída nos anos 70 por iniciativa de alguns padres e pastores do Oeste do Paraná, dentro da perspectiva das Comunidades Eclesiais de Base (CEBs). A própria criação da CPT-PR em 1976, num encontro da pastoral rural em Ponta Grossa, foi ecumênica, tendo à frente dois coordenadores: o Padre João Mors de Medianeira, e o Pastor Gernote Kirinus, de Marechal Cândido Rondon/Entre Rios, previa várias atividades conjuntas, por exemplo, o encontro de padres e pastores da área atingida com dirigentes da Itaipu. A única história conflitiva era Missal, uma colonização criada somente para católicos. Os primeiros não-católicos que conseguiram comprar terras e/ou terrenos ali tiveram que fingir que eram católicos. Mas, de modo geral, a realidade social fez com que também ali surgisse abertura para cooperar nas causas sociais.

4- As igrejas (Católica e Luterana) configuravam-se como as únicas instâncias organizadas a frente da sociedade na década de 1970? Dito de outra forma, sindicatos, câmara de vereadores, prefeitos, deputados, tinham presença de interlocutores junto aos problemas mais prementes dos "cidadãos oestinos"? Ou então, é correto afirmar que estes órgãos de poder instituídos eram tímidos frente às necessidades do povo? Caso sim, seria pelo 'peleguismo' sindical, ou consciência não formada e/ou pressão militar? 
R- De fato, esperava-se das igrejas a maior iniciativa. Não digo que os dirigentes sindicais fossem "pelegos" (com raras exceções), mas apenas atrasados, despreparados, cuidando de uma estrutura assistencialista. Mas, no momento em que surgiram chapas "autênticas" apoiadas pela igreja, a Federação dos Trabalhadores na Agricultura do Estado do Paraná (FETAEP) enviou pessoas que instruíram esses sindicalistas atrasados para se manterem no poder. Um exemplo contundente foram as Notas Promissórias Rurais (NPRs): a CPT fez uma cartilha (Você e as NPRs), explicando o que estava por trás: frigoríficos faliram fraudulentamente e os bancos cobraram dos avalistas, os agricultores, que nem sabiam que haviam assinado o aval. Aí o Padre Adriano ${ }^{2}$ convocou uma reunião em Medianeira, e os agricultores compareceram em grande número, agarrando-se a essa cartilha como única tábua de salvação "Só a igreja pode nos ajudar..."

\section{5- Em que medida a divisão da diocese de Toledo e formação de outras duas novas dioceses (Foz do Iguaçu e Cascavel) em 1978 possibilitou a consolidação de um Igreja mais envolvida com o problema dos expropriados?}

R- Acho que a divisão da diocese possibilitou, sim, uma ação mais próxima das lutas sociais, pelo menos na diocese de Foz.

\footnotetext{
${ }^{2}$ Padre Adriano Van de Ven foi vigário e, em seguida, pároco na cidade de Medianeira. Exerceu a função de coordenador pastoral da diocese de Foz do Iguaçu entre os anos de 1978 a 1982. Esta menção ao padre Adriano não é ocasional nem fortuita porque revela um dos pontos fundamentais para se entender a mobilização e a consolidação do Movimento dos Agricultores Sem Terra do Oeste do Paraná (MASTRO) como um dos movimentos tributários da gestação do Movimento dos Sem Terra (MST).
} 


\section{6- Teria sido a divisão territorial que possibilitou a uma ação mais ativa frente} aos expropriados ou, por outro, a visão de Dom Armando Círio, então bispo de Toledo, era mais 'espiritualista' que social?

R- Não conheci muito bem Dom Armando $^{3}$. Sei que fazia a ação pastoral mais tradicional: visita as capelas. Por ocasião da luta dos suinocultores (1980), fizemos um culto ecumênico na praça de Toledo com ele e o Pastor Presidente da IECLB (Augusto Kunert), no qual ele manifestou apoio à causa suinocultores. Logo em seguida decidiram bloquear os frigoríficos do Oeste (inclusive o da Sadia, durante 4 dias, até que chegasse o exército). Para não dispersar os acampados e o movimento, conseguimos, com o coordenador da diocese, permissão de acampar dentro da catedral, que ainda estava em construção.

\section{7- Como o senhor definiria o papel de Dom Olívio Fazza à frente da diocese de Foz do Iguaçu?}

R- Não sei precisar o papel dele. Mas foi muito corajoso e coerente. Não permitia ser fotografado ao lado de oportunistas políticos. Respeitou as decisões que vinham das bases, das equipes de pastoral, do movimento de atingidos (por exemplo, quando marchamos para Foz em março de 1981). Quando os atingidos das NPRs estavam concentrados na igreja de Medianeira (mais de 800 pessoas) e a igreja foi cercada pela PM, Dom Olívio saiu da igreja e questionou o comandante. A explicação de sempre: Estava cumprindo ordens. Ordens de quem? - Sem resposta. Por que motivo? - Para evitar distúrbios.... Teria retrucado Dom Olívio: Mas lá dentro estão

\footnotetext{
${ }^{3}$ Dom Armando Círio foi empossado como primeiro bispo de Toledo em 1960. Com a criação da diocese de Cascavel em 1978 e sua elevação a arquidiocese no ano seguinte, em 1979, Dom Armando é eleito novamente a função de primeiro bispo e, em seguida, primeiro arcebispo da arquidiocese de Cascavel.
} 
nossos melhores cristãos, ministros de eucaristia, líderes comunitários, etc. Insistiu em saber quem dera a ordem. Essa conversa foi comunicada à assembléia dentro da igreja, com o sistema de alto-falantes ligado - também para fora dela. De fato o desespero dos agricultores era tamanho, que ameaçavam trancar o Banco do Brasil, bloquear a BR 277, etc. O episódio mostra a firmeza de Dom Olívio e também sua sensibilidade pastoral. Pelo que diziam os padres, Dom Olívio de fato valorizava a caminhada pastoral e não tentava impor um modelo hierárquico. Outro exemplo: antes da primeira grande assembléia dos atingidos pelo lago de Itaipu, em outubro de 1978, estávamos reunidos na casa paroquial de Medianeira com todos os integrantes da equipe da CPT (inclusive com o pastor Secretário de Missão da IECLB, que pernoitou ali e me disse, apreensivo, que era a primeira vez na vida em que dormiria na casa de um padre). Preparamos os detalhes/metodologia da Assembléia (deixar o povo falar, evitar os penetras da polícia federal), que havia sido convocada pelo Pastor Kurt e pelo Padre Valentin. No mesmo dia a polícia pressionou Dom Olívio em Foz do Iguaçu para que cancelasse o evento. Ele disse que não faria isso, porque era a decisão de uma equipe, que tinha autonomia. Para ter uma idéia do clima de pressão: o pastor Kurt, que assinou a convocação para assembléia, foi intimado a comparecer na delegacia de Marechal Cândido Rondon no mesmo dia e horário da assembléia. Foi aí que eu, novato, tive que assumir a direção da reunião. Dom Olívio se fez presente, e como o encaminhamento era conseguir uma audiência com o Presidente Geisel, uns 10 dias depois (em razão do desvio do canal do rio Paraná) e outros políticos/sindicalistas oportunistas se ofereceram para intermediá-la, Dom Olívio dispensou-os e disse que conseguiria pelos seus contatos. Isso de fato aconteceu, mas a audiência foi com o ministro das Minas e Energia (Shigeaki Ueki). 
8- Dom Olívio era uma voz isolada no episcopado paranaense? Pode-se dizer que o Regional Sul II ligado a Conferência Nacional dos Bispos do Brasil (CNBB) deu respaldo legal para as suas ações?

R- Entre o episcopado Dom Olívio não se destacou muito inicialmente. Também havia Dom Ladislau Bienarski, e o próprio Dom Pedro Fedalto ${ }^{4}$, ao qual recorríamos com freqüência, porque os secretários do Regional da Conferência Nacional dos Bispos do Brasil (CNBB) eram os padres Ângelo e Miguel, que abriam muitas portas. Em alguns episódios/conflitos nos anos 80 Dom Olívio tomou a frente, até para negociar o não-despejo de sem-terras com o governador Álvaro Dias. Em geral, fazia isso por ter sido designado pelos demais bispos para acompanhar a CPT. Também Dom Frederico Helmel de Guarapuava passou a ser um lutador pelos semterra. No início da CPT, o bispo que a acompanhava, em nome da CNBB, era Dom Agostinho José Sartori (bispo de Palmas e Francisco Beltrão). Também Dom Walter Ebejer de União da Vitória e o bispo de Apucarana, Dom Domingos Wisniewski, tomaram atitudes corajosas, apesar de alguns momentos de insegurança ou discordância. Vale lembrar que no começo (1985) as romarias da terra eram ecumênicas, inclusive com celebração da eucaristia. Ou seja, apesar de alguns bispos conservadores, o Regional Sul II dava respaldo aos bispos que acompanhavam causas sociais.

\footnotetext{
${ }^{4}$ Dom Pedro Fedalto foi eleito presidente do Regional Sul II em 1968 exercendo o cargo até 1995.
} 
9- Há uma referência no livro de Guiomar Germani ${ }^{5}$ em que ação de Dom Olívio junto aos expropriados de Itaipu teria sido conservadora no episódio do primeiro acampamento em Santa Helena entre 14 a 28 de julho de 1980. Parafraseio as passagens abaixo:

- Dom Olívio não era assessor e somente mediava algumas negociações entre agricultores e a Itaipu. Daí não conhecer bem a realidade de cada caso. Por isso a proibição por parte da Itaipu da participação do pastor Fuchs na comissão dos agricultores nas negociações ser lamentável dado seu conhecimento e agilidade. Assim cinco agricultores, mal assessorados, Dom Olívio mais como mediador não teriam conseguido resultados positivos junto a binacional (p. 138 - 139).

- $\quad$ A autora estranhou a realização da missa de ação de graças, no dia 29 de julho, antes de acontecer a Assembléia como sinal de concordância das propostas de Itaipu. Isso teria desconsiderado a autonomia da Assembléia e incentivado o recuo da marcha. "Esta atitude foi motivada principalmente pela posição de D. Olívio Fazza (bispo de Foz do Iguaçu), que, após a reabertura do diálogo, não se mostrava mais favorável à marcha pacífica para Foz; sua posição foi de freio ao movimento que, apesar de contar com o apoio dos deputados, não se sentiu encorajado a seguir a marcha sem o apoio oficial da Igreja" (p. 141).

PERGUNTO: Qual é sua avaliação sobre as considerações da autora?

${ }^{5}$ O livro a que se faz referência é: GERMANI, Guiomar. Expropriados, terra e água: conflitos de Itaipu. 2 ed., Salvador: Edufba/Ulbra, 2003. 
R- Não concordo totalmente com a Guiomar. Obviamente Dom Olívio tinha o desejo de evitar o conflito, e Itaipu recorria a ele como mediador. Por outro lado, também os agricultores não eram militantes de longa data e não queriam se arriscar numa marcha daquelas. Para eles, a ação já era extrema. Na negociação conseguiram boa parte do que reivindicavam. Em negociações posteriores, sem Dom Olívio, a comissão de agricultores também não obteve $100 \%$ do que pediu. Nós que os assessorávamos, e os deputados, discordávamos da posição deles, de se contentarem com menos, quando tinham a faca e o queijo na mão. Por outro lado, respeitávamos sua atitude, porque a luta era deles, não nossa. A Guiomar não participou desse processo posterior, e por isso tem uma visão mais restrita.

\section{0-A proposta era formar lideranças do meio dos próprios agricultores...}

R- Exatamente isso. Lembrei que na ocasião das "conquistas" questionadas pelo então pastor e deputado Kirinus, outros deputados e pessoas com visão da correlação de forças também discordaram da atitude dos atingidos, de se contentar com menos do que poderiam ter alcançado. Mas na ocasião, embora concordando com o questionamento, eu defendi os agricultores (por exemplo, deputado Nelton Friedrich compreendeu isso) por uma questão de respeito a eles como sujeitos. A luta era deles, não nossa. Acho que Dom Olívio teve uma influência nesse "contentar-se com menos" (não sei precisar quanto), porque retornaram da reunião com a Itaipu com a idéia definida. Para os cinco líderes foi um grande passo. Jamais haviam liderado nada, e o peso da responsabilidade de poder apresentar aos outros saldos positivos era enorme. 
11-Em que medida o projeto Arca de Noé teve importância frente à organização dos expropriados de Itaipu? O pastor Kurt Hattje teria sido seu protagonista? A Igreja Católica participou junto deste projeto? Teve adesão popular? Caso tenha sido importante, por que as menções são tão esparsas? (Mazzarollo ${ }^{6}$ assim se refere sobre o Projeto: Em 31/03/78 houve encontro em Rondon. Criaram o Projeto Arca de Noé para salvar os agricultores do dilúvio anunciado pela Itaipu. Este definia objetivos, justificativa, métodos e recursos. Diz a justificativa: Sem colocar em dúvida um empreendimento de tamanha importância para a Nação, como é Itaipu, nós nos importamos, de fato, com o homem. Eles merecem nossa consideração, nosso apreço, nosso empenho).

R- O projeto Arca de Noé foi idealizado pelos dois pastores, Kurt e Kirinus, e depois implementado mais pelo Kirinus. Kurt assumiu a CPT apenas por 3 meses (julho a setembro de 1978), quando Kirinus se tornou candidato a deputado e eu ainda estava em Santa Catarina. A adesão se deu nos eventos já mencionados, de encontro do clero com a direção da Itaipu. Na época, um dos lutadores fortes desse projeto era o Padre Adriano (Medianeira), apesar de sua paróquia não ser atingida pelo lago. Fala-se pouco do Pastor Kurt porque saiu rapidamente de cena, aceitando convite da colonizadora Sinop para acompanhar fiéis até o Mato Grosso.

12-Seu nome, pastor Fuchs, aparece constantemente associado ao nome do padre Valentim Dal Pozzo, pároco de Santa Helena. Pergunto:

Como era a relação entre o pastor e o padre? Atuavam juntos? Dividiamse tarefas?

\footnotetext{
${ }^{6}$ Refere-se ao livro de MAZZAROLLO, Juvêncio. A taipa da injustiça: esbanjamento econômico, drama social e holocausto ecológico em Itaipu. 2 ed., São Paulo: Loyola, 2003, p. 58 - 60.
} 
Junto ao padre Valentim havia outros padres envolvidos na movimentação em favor dos expropriados? Ele chegava a ser porta voz de Dom Olívio Fazza?

Havia movimentos de Comunidades Eclesiais de Base (CEBs) em Santa Helena?

R- Como o padre Valentim tinha o dobro de capelas e metade das distâncias que eu, nós dois corríamos o tempo todo. Não tínhamos tempo de planejar ações conjuntas. As ações aconteciam muito em cima do momento. Ao eclodir o bloqueio ao escritório de Santa Helena e julho de 1980, fiz contato com as emissoras de rádio de madrugada a partir da casa dele. No caso dos índios do Ocoí, emprestei a kombi da paróquia dele. Algumas reuniões dos agentes de pastoral aconteceram na casa do padre Valentim, a Igreja Católica sediou a primeira assembléia, depois os líderes do movimento geralmente preferiram anunciar as reuniões para o salão paroquial da igreja luterana. Em Santa Helena não havia propriamente o movimento de CEBs como em Medianeira, mas uma renovação de catequese, com ministros de culto e eucaristia. Isso fez com que a maioria dos líderes do movimento viesse da Igreja Católica. Na fase de Santa Helena, poucos padres se apresentaram em público na defesa dos atingidos. Não lembro que algum padre tenha se apresentado como porta-voz de Dom Olívio.

13-Pelo que as leituras indicam, o evento de 14 a 28 de julho de 1980 em Santa Helena, foi um episódio extraordinário em termos midiáticos e, sobretudo, na sensibilização dos expropriados. O senhor aparece como um grande idealizador deste acontecimento. Pergunto: 
- Como eram organizadas a relação fé e ação neste acampamento? Podese dizer que fé, política e consciência estavam envolvidas?

- Qual era a programação normal diária?

- Fontes apontam para constantes orações/cultos/missas celebradas por padres, pastores e bispos de projeção local, regional e nacional. Quem, como e porque se adotou esta estratégia de trazer personalidades externas ao movimento?

- Havia pressão militar forte durante os dias de acampamento? Por que o senhor freqüentemente não era autorizado ou admitido para fazer parte das comissões de negociação junto a Itaipu?

Havia estudos, discussões teóricas, formação humana no acampamento? Em momentos anteriores ou posteriores ao acampamento, havia reuniões/encontros de conscientização dos expropriados?

R- Sim, havia uma forte ligação entre fé e luta social e política. Tanto é que havia cultos e outras celebrações. Também boa parte dos líderes (especialmente Marcelo Barth, que tem irmão padre) fazia essa ligação. Um agricultor poeta de minha igreja fazia versos ligando a luta com o Pai Nosso. Tudo girava em torno da "rádio" do acampamento. Muita improvisação, artistas populares, etc. Mesmo um pastor da outra igreja luterana, de Pato Bragado, impedido por seus superiores de participar de cultos ecumênicos, veio ao acampamento e em pouco tempo foi anunciado um culto luterano oficiado por ele. Quando não tinha pastor (igreja pentecostal), um leigo participava de celebrações. No dia 25 de julho (1980), houve a grande marcha pela cidade em Santa Helena, com apoio organizado especialmente pelo padre Adriano de Medianeira. Mas ele não foi o grande idealizador do acampamento de Santa 
Helena. A Guiomar despediu-se depois de um mês de pesquisas, dizendo que "está tudo morto". Quatorze (14) dias depois estourou o movimento, vindo de dois pontos que ninguém esperava: dos donos de chácaras, que até então tinham feito uma luta em separado, e de Itacorá, onde ainda não havia desapropriações, por causa da falta de titulação. A iniciativa foi deles, com muita fé em Deus. A notícia correu rapidamente, e os dois grupos tiveram adesão de muitos que já tinham feito acordo com a Itaipu e ainda não haviam recebido o cheque.

\section{4- O Conselho Indigenista Missionário (CIMI) não teve presença mui tímida na} região?

R- Sim, a presença do CIMI foi pequena. Valeu por terem trazido um cacique guarani de São Paulo de 80 anos de idade, que conseguiu um resgate cultural/religioso: ensinou cantos e rezas. Isso deu aos índios uma identidade e força de resistência. O laudo antropológico dos Avá-guarani e o apoio da Comissão Justiça e Paz também foram importantes. Eu fiquei como pessoa de contato dos índios. Um dia vieram dois deles apavorados à minha casa em Santa Helena, por terem sido ameaçados de morte pelo cacique (mestiço), que exigia de arma em punho que trabalhassem na roça dele. Com a kombi levei um grupo até Foz do Iguaçu. Passamos o dia sendo enviados de uma polícia à outra, e finalmente retornamos à Polícia Federal. O delegado estava ao telefone com a Funai (Fundação Nacional do Índio) de Curitiba, que reconhecia apenas quatro indígenas. Um deles estava comigo, era um jovem de uns 20 anos. Aí o delegado interrogou os demais. A um índio de idade o delegado disse que ele não era oficialmente índio. Ele respondeu que era avô do jovem. Depois convencemos o delegado de enviar policial até o Ocoí no dia seguinte. 
Foram e prenderam o falso cacique. Deve ter sido torturado, porque alguns dias depois veio a Santa Helena um sobrinho dele, rapaz forte, a quem eu já dera carona, tentando tirar satisfações. Eu teria mandado a polícia bater no tio dele. O secretário da paróquia disse que ele estava realmente furioso. Felizmente eu não estava em casa.

15- A partir de 1980 surgem mais ativamente outras entidades envolvidas como a Comissão Justiça e Paz, Fetaep, Sindicatos e Comissão Pastoral da Terra. Quais razões justificariam esta presença 'tardia'? O fim do regime trazia ânimos? As eleições eram oportunidades de mostrar quem estava ao lado do agricultor?

R- A FETAEP esteve presente desde o início, ajudou a desmascarar a farsa legal da Itaipu em fevereiro de 1979, por estar desapropriando sem decreto. De imediato (março) o Geisel assinou o decreto (explicação: devido à validade de cinco anos, retardaram ao máximo, temendo não concluir as desapropriações nesse prazo). Também ajudou a denunciar as colonizadoras "idôneas". Na época havia duas posições na FETAEP (Lázaro Dumont era pelego, mas seu vice-presidente, Agostinho Bokowski, era combativo. Por isso as ambigüidades). Sindicato engajado era somente o de São Miguel do Iguaçu, na pessoa do secretário (não do presidente), que ajudou a formar o Movimento dos Sem Terra (Mastro) em 1980. A CPT foi a grande presença desde o início (1977). O presidente da Comissão Justiça e Paz, Wagner D’Angelis, foi contratado pela CPT em 1979 para prestar assessoria jurídica. Um advogado de Palotina foi indicado pela Comissão Justiça e Paz para dar assessoria permanente ao Movimento Justiça e Terra. Por isso não concordo que 
essas entidades entraram em cena apenas depois de 1980. A verdade é que 1981 foi o período de maior força e intensidade das ações. A idéia do "movimento" estava plantada. Ainda era governo Figueiredo, mas de fato já se falava de abertura.

16- A respeito do acontecimento do Trevo da Vergonha ocorrido entre os meses de março a maio de 1981 em Foz do Iguaçu, pode-se destacar um papel pró-ativo da Igreja Católica? Segundo consta Dom Pedro Fedalto teria estado num momento naqueles 54 dias de luta. É correto afirmar que a hierarquia católica estava ao lado dos expropriados? A hierarquia teria intervindo junto ao governador do Estado Ney Braga?

R- Sim. Dom Pedro veio com diversos bispos, uma enorme concentração popular e celebração. Interveio diversas vezes com o governador. Ele se comprometeu a destacar o Instituto de Terras, Cartografia e Florestas (ITCF) para, com os critérios da Itaipu, fazer um levantamento do preço de terras. O ITCF demonstrou que a Itaipu não respeitava nem seus próprios "critérios", praticando preços defasados. No trevo organizávamos celebrações diárias, com ou sem padre, com ou sem pastor. Na Semana Santa veio o padre Hans de Marechal Cândido Rondon, transformando o fusca em confessionário (como os bodes expiatórios dos tempos bíblicos levavam embora os pecados do povo). Antes disso, merece o registro a vinda de Dom José Brandão de Propriá-SE, nos meses de maio e junho de 1980. Fizemos várias reuniões (Porto Mendes, Itacorá, etc.), nas quais ele falou da barragem de Sobradinho, da indiferença dos governantes, de que o povo tinha de ser mexer... O povo desses grotões, que raramente via um bispo, apenas nas crismas, ficou fascinado. Aí um bispo fala da luta do povo, denuncia o presidente da república, 
critica o capitalismo e a mídia, desmascara a Itaipu. A cada frase o queixo das pessoas caía mais um pouco.

17- O senhor poderia descrever como foi o dia 07 de abril de 1981 quando houve a "Caminhada pela Paz" em Foz do Iguaçu reunindo aproximadamente 5 mil pessoas entre padres, pastores e outros?

R- Não me lembro do número de pessoas, mas foi marcante, porque significou a virada da opinião pública. Nos primeiros dez (10) dias do acampamento o prefeito (Foz do Iguaçu) negou água. Depois veio a pressão por telex, telefone, de igrejas, parlamentares (por exemplo o senador Nivaldo Krüger), etc. Foi uma demonstração de força. Soubemos depois que o Conselho de Segurança Nacional (SNI) passou a pressionar a Itaipu para acabar logo com isso. 